\title{
ANALISA DAN KOMPARASI PC ROUTER UBUNTU DENGAN ROUTER KOMERSIL (BELKIN) DI JARINGAN LAN
}

\author{
Feri Fahrianto, M.Sc. ${ }^{\text {a }}$, Victor Amrizal, M.Kom ${ }^{\text {b }}$ \\ ${ }^{a}$ Staff Pengajar Program Studi Teknik Informatika \\ Fakultas Sains dan Teknologi \\ Universitas Islam Negeri Syarif Hidayatullah Jakarta \\ Tel : (021) 32977989 \\ e-mail :feri.fahrianto@uinjkt.ac.id \\ ${ }^{b}$ Staff Pengajar Program Studi Teknik Informatika \\ Fakultas Sains dan Teknologi \\ Universitas Islam Negeri Syarif Hidayatullah Jakarta \\ Tel : (021) 32977989 \\ e-mail :ersebros@gmail.com
}

\begin{abstract}
Router is a device that used to forward a packet from one network to other network such as from WAN to LAN and vice versa. A lot of commercial routers are available in market from low-end to high-end router. As an alternative router can be build and working properly from old PC installed with Unix-based operating system called as PC router. The quality of service of both commercial router and PC router are measured in this paper in order to find the characteristic of both routers. The result found out that commercial router has asymmetric speed for download and upload but PC router relatively has symmetric speed of download and upload.
\end{abstract}

Keywords: Router, LAN, WAN, QoS

\section{Pendahuluan}

Router adalah alat yang digunakan untuk meneruskan suatu paket dari suatu network ke network lain atau dari LAN ke WAN dan sebaliknya. Perkembangan penggunaan router berbasis open source juga berkembang dengan pesat termasuk pemanfaatan PC (Personal Computer) lama menjadi suatu yang lebih berguna seperti router dan berbagai service lainnya. Pemanfaatan penggunaan router open source sebagai router yang murah, handal, tepat guna yang dapat dikonfigurasi berdasarkan pada tingkat kebutuhan tanpa mengurangi efektifitas dan kegunaannya merupakan salah satu alternatif tersendiri selain dapat mengurangi biaya operasional dalam pembelian software ataupun hardware selain itu dapat menggunakan PC lama menjadi router yang mampu bersaing dengan router komersial lainnya. Permasalahaan yang timbul dari paparan diatas adalah bagaimana menganalisa perbandingan PC router berbasiskan Linux Ubuntu dengan router komersial dengan merek belkin untuk traffic atau transmisi data yang akan di hasilkan dari kedua router tersebut diatas dan kemudahan dalam menkonfigurasi kedua router tersebut di jaringan LAN.

\section{Studi Literatur}

\subsection{Jaringan Komputer}

Network dapat diartikan sebagai jaringan. Di dalam ilmu komputer akan disebut sebagai computer network apabila ada 2 komputer atau lebih yang saling berhubungan satu sama lain 
dan dapat menggunakan perangkat lain secara bersama. Kelompok komputer akan didaftar ke dalam kelompok atau grup yang sama. Kondisi seperti itulah yang disebut dengan computer network atau jaringan computer (Nugroho, B. 2005). Tujuan dari jaringan komputer adalah:

a. Membagi sumber daya: contohnya berbagi pemakaian printer, CPU, memori, harddisk.

b. Komunikasi: contohnya surat elektronik, instant messaging, chatting.

c. Akses informasi: contohnya web browsing.

Ada 3 macam jenis Jaringan / Network berdasarkan skala area yaitu : (Nugroho, B. 2005)

a. LAN (Local Area Network)/ Jaringan Area Lokal. Sebuah LAN, adalah jaringan yang dibatasi oleh area yang relative kecil, umumnya dibatasi oleh area lingkungan seperti sebuah perkantoran di sebuah gedung, atau sebuah sekolah, dan biasanya tidak jauh dari sekitar $1 \mathrm{~km}$ persegi.

b. MAN (Metropolitan Area Network)/ Jaringan area Metropolitan Sebuah MAN, biasanya meliputi area yang lebih besar dari LAN, misalnya antar wilayah dalam satu propinsi.

c. WAN (Wide Area Network)/ Jaringan area skala besar Wide Area Networks (WAN) adalah jaringan yang lingkupnya biasanya sudah menggunanakan sarana satelit ataupun kabel bawah laut. Biasanya WAN agak rumit dan sangat kompleks, menggunakan banyak sarana untuk menghubungkan antara LAN dan WAN kedalam komunikasi global seperti Internet.

\subsection{Komponen Jaringan}

Komponen jaringan adalah komponen yang memberikan dukungan terhadap fungsi kerjanya sistem jaringan yang meliputi model jaringan, topologi, media transmisi, arsitektur jaringan dan protocol adapun Jenis Jaringan berdasarkan kebutuhan (Nugroho, B. 2005) dapat di paparkan sebagai berikut :

\section{a. Jaringan Peer To Peer}

Peer-to-Peer atau disebut point to point merupakan jenis jaringan yang tidak melibatkan sumber daya terlalu tinggi. Sering disingkat menjadi P2P atau point to point dimana jaringan yang terdiri atas dua komputer atau lebih yang menggunakan program yang sama atau menggunakan jenis program yang sama untuk saling berkomunikasi dan berbagi data. Setiap workstation/ komputer yang terhubung tidak dibatasi oleh hak akses. Setiap komputer, yang dalam arsitektur peer-to-peer disebut dengan "Peer", dianggap sama dan setiap peer juga bertindak sebagai server bagi peer lainnya di dalam jaringan tersebut, yang bertindak sebagai kliennya.

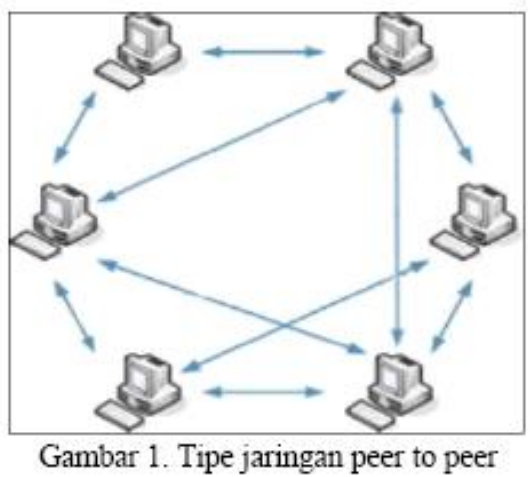

b. Jaringan Client-Server atau Klien-Server Client-server merupakan sebuah paradigma dalam teknologi informasi yang merujuk kepada cara untuk mendistribusikan aplikasi ke dalam dua pihak: pihak client dan pihak server. Dalam model client-server, sebuah aplikasi dibagi menjadi dua bagian yang terpisah, tapi masih merupakan sebuah kesatuan yakni komponen client dan komponen server. Komponen klien juga sering disebut sebagai front-end, sementara komponen server disebut sebagai back-end. Komponen client dari aplikasi tersebut dijalankan dalam sebuah workstation dan menerima masukan data dari pengguna.

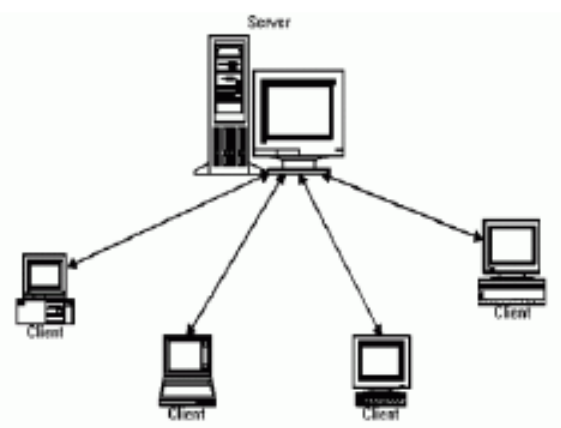

Gambar 2. Komputer client terhubung ke server pada jaringan client/ server 


\subsection{Topologi Jaringan}

Topologi jaringan adalah model/ metode menghubungkan komputer ( secara fisik ) di dalam suatu jaringan komputer. Menurut bentuknya topologi jaringan dibedakan menjadi tujuh macam, yaitu :
a. Topologi Star
b. topologi Loop
c. Topologi Ring
d. Topologi Bus
e. Topologi Hierarchial Tree
f. Topologi Web
g. Topologi Meta

\subsection{Media Transmisi}

Media transmisi adalah media yang digunakan untuk berkomunikasi dan untuk pengiriman data. Pada sistem jaringan.media transmisi adalah media kabel coaxial dan kabel. Bila sumber data dan penerima jaraknya tidak terlalu jauh dalam hal area yang lokal, maka dapat digunakan kabel sebagai media transmisi. Macam-macam kabel yaitu :

\section{a. Twisted Pair Cable}

Media ini yang paling banyak dikenal karena merupakan kabel telepon yang sudah banyak dikenal dan digunakan. Jenis kabel ini relatif tidak mahal tetapi hanya dapat digunakan untuk jarak pendek, mudah terpengaruh oleh gangguan dan kecepatan data yang dapat didukungnya terbatas.

\section{b. Coaxial Cable}

Media ini paling banyak digunakan untuk Local Area Network. Kabel sering dipakai oleh industri pertelevisian CATV (Cable TV). Data yang dikirim melalui media ini relative mudah diambil atau dibajak sehingga keamanan data tidak terjamin sepenuhnya. Data rate maximum yang diperkirakan dapat mencapai $30 \mathrm{Mbps}$

\section{c. Fiber Optic Cable}

Media ini dianggap paling ideal, karena selain mempunyai beberapa keuntungan seperti ukuran yang kecil jarak capai data yang jauh sekali serta kecepatan transfer data tinggi. Jenis kabel ini mempunyai harga yang relative mahal dan masih dalam tahap teknologi perkembangan. Data rate maksimum diperkirakan dalam beberapa akhir ini mencapai $100 \mathrm{Mbps}$

\subsection{Arsitektur Jaringan}

Sebagai pengatur jaringan untuk menggambarkan sebuah jaringan komputer. Dari sistem jaringan berhubungan dengan teknologi jaringan, NIC (Network Interface Card), dan pemilihan kabel yang dipergunakan untuk pembuatan jaringan yang paling banyak dipergunakan, mudah dikenal, dipahami yaitu model referensi OSI (Open Sistem Interconnection) dan model TCP/ IP. OSI (Open System Interconnection) Referensi Model pada prinsipnya menjelaskan bagaimana informasi yang dilepaskan sebuah software aplikasi dalam komputer bergerak (melintasi media jaringan) ke sebuah software aplikasi dalam computer lainnya. OSI Referensi model merupakan sebuah model konseptual yang terdiri atas tujuh layer komunikasi, di mana masing masing layer menetapkan fungsi khusus dalam jaringan. (Rafiudin, R. 2006).

\section{a. Model Referensi OSI}

OSI (Open Sistem Interconnection) adalah standart arsitektur jaringan yang dikeluarkan oleh International Standards Organizations (ISO), dapat diartikan sebagai sistem yang terbuka untuk berkomunikasi dengan sistem sistem lainnya. Tujuan OSI yaitu :

1. Menghilangkan ketergantungan pada suatu produsen.

2. Mengikuti perkembangan tanpa harus mengorbankan perangkat keras atau perangkat lunak yang sudah ada.

Untuk keperluan itu maka dibuatlah spesifikasi yang bersifat terbuka yang berisi bakuan-bakuan tentang kualitas dan metode kerja suatu sistem jaringan. Setiap layer mempunyai bakuan bakuan sendiri tetapi bakuan masih memungkinkan untuk berkomunikasi dengan layer yang lain. OSI membagi komponen jaringan dalam 7 layer yaitu :

\section{Physical Layer}

Physical Layer merupakan lapisan terbawah dari model referensi OSI yang merupakan fungsi elektris, mekanis dan prosedur untuk menbangun, memelihara dan melepaskan sirkuit komunikasi dan untuk mentransmisikan informasi dalam bentuk digit biner dari lapisan atasnya dari satu sisi ke sisi lainnya.

\section{Data Link Layer}

Walaupun Phisical Layer memberikan layanan dengan memberikan data mentah dalam bentuk 
aliran bit, data link layer ini bertugas menjadikan Phisical Layer berguna dan memberikan sarana untuk mengaktifkan, memelihara dan memutuskan suatu hubungan.

\section{Network Layer}

Network Layer berfungsi mengatur hubungan antara pengirim dan penerima menentukan rute dari sumber ke tujuan, menyediakan sarana hubungan antar jaringan (inter networking) dan menangani kemacetan apabila terjadi kepadatan lalu lintas data (paket)

\section{Transport Layer}

Bertugas dalam mengatur hubungan antar komputer ke computer (end-to-end). Fungsi dari layer ini adalah menerima data dari session layer, memilah menjadi satuan-satuan yang lebih kecil dan melewatkan pada network layer, kemudian menggabungkan kembali data tersebut. Lapisan ini bertugas mengawasi kualitas pengiriman.

\section{Session Layer}

Layer ini bertugas menyediakan struktur kecuali untuk membangun, memelihara dan memutuskan hubungan antar aplikasi, menentukan jenis koneksi jaringan yang digunakan.

\section{Presentation Layer}

Pada lapisan ini bertugas memperhatikan sintak dan semantik informasi yang dikirim agar dimengerti, melakukan kompresi data untuk efisiensi penggunaan saluran. Lapisan ini merupakan lapisan OSI yang paling jarang diterapkan karena kebanyakan kasus aplikasi jaringan melakukan fungsi-fungsi yang dapat berhubungan dengan presentation

\section{Application Layer}

Berfungsi untuk melayani pemakai dengan memberikan pelayanan informasi tersebar yang berhubungan dengan aplikasi pusat transfer file dan aplikasi untuk email serta pengolahan

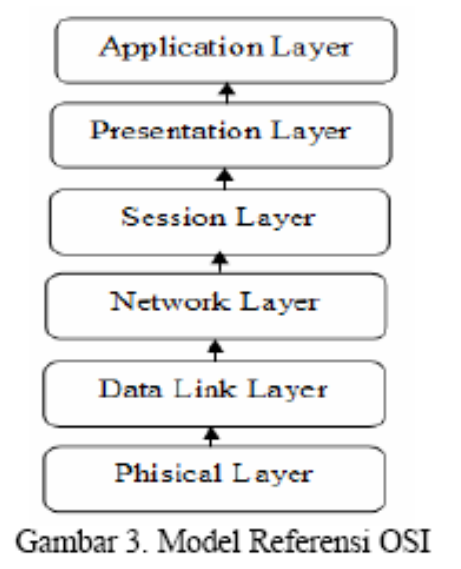

b. Model Referensi TCP/IP

Jaringan komputer yang berada dalam internet memiliki tipe yang berbeda beda sehingga dibutuhkan suatu aturan tertentu yang mendefinisikan bagaimana sesuatu semestinya dilakukan. Aturan ini dinamakan protocol. Protokol merupakan istilah standar dalam konteks komunikasi data diantara mesin mesin dalam jaringan. Protocol yang digunakan dalam jaringan internet TCP/ IP. Transmision Control Protocol/ Internet Protocol (TCP/IP) merupakan protocol jaringan yang luas digunakan dalam LAN, WAN, maupun Internet. (Rahmat Rafiudin, 2006 : 11) dengan kata lain serangkain protokol dimana setiap protokol melakukan kegiatan sebagian dari keseluruhan tugas komunikasi jaringan yang digunakan pada jaringan komputer ARPANET. Protokol TCP/IP terdiri dari 4 layer yaitu :

\section{Lapisan Host to Network}

Merupakan lapisan terbawah dari hierarki protocol TCP/ IP dan merupakan gabungan dari Phisical Layer dan Data link Layer pada referensi OSI yang berfungsi mendefinisikan cara memindahkan data antara komputer yang terhubung ke media network fisik yang sama.

\section{Internet Layer}

Fungsi dari Internet Layer yaitu mendefinisikan format paket resmi (memindahkan data) dan protokol resmi (pengkodean) yang digunakan yaitu IP.

\section{Transport Layer}

Transport later berisi 2 protocol end toend yaitu TCP (Transmision Control Protocol) dan UDP (User Data Protocol) yang mengatur 
komunikasi jaringan. TCP menyediakan pelayanan pengiriman data yang andal dengan deteksi dan koreksi kesalahan dari ujung ke ujung (end to end). UDP menyediakan pelayanan pengiriman datagram yang connectionless dan tanpa dilengkapi deteksi dan koreksi.

\section{Application Layer}

Application layer merupakan lapisan teratas, merupakan penyatuan dari tiga buah lapisan OSI (session, presentation, application) yang berisi protocol tingkat tinggi yang disesuaikan dengan aplikasi yang telah diterapkan seperti layer dibawah ini :

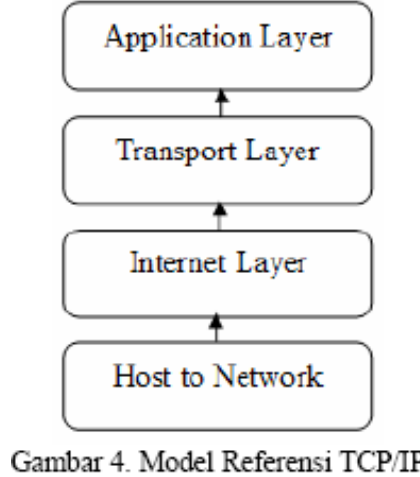

\subsection{Pengalamatan IP (IP Address)}

Internet protocol menggunakan IP Address sebagai identitas. Pengiriman data akan dibungkus dalam paket dengan label berupa IP Address si pengirim dan IP Addres si penerima. Apabila si penerima melihat pengiriman paket tersebut dengan identitas IP Address yang sesuai maka datagram akan diambil dan kemudian disalurkan ke TCP atau UDP melalui port, dimana aplikasi menunggunya. IP Address terdiri dari 2 bagian yaitu :

a. Network Id ( Identitas Jaringan)

b. Host Id ( Identitas Komputer )

Penulisan IP Address terbagi atas 4 angka, yang masing-masing mempunyai nilai maksimum 255 (maksimum dari 8 bit)

IP Adress : 255.255.255.255

Karena setiap angka mempresentasikan 8 bit, maka jumlah total IP Address adalah 32 bit ditulis sebagai berikut :

00000000000000000000000000000000

11111111111111111111111111111111
IP Address dirancang untuk mempunyai class yang didefinisikan sebagai berikut

1. Class A

a. Bit pertama dari IP Address adalah 0

b. Jadi jaringan dengan IP yang byte pertama : 0 $-127$

c. Hanya ada kurang dari 128 jaringan dengan Class A.

d. Setiap jaringan Class A bisa mempunyai jutaan host

2. Class B

a. Bit pertama dari IP Address adalah 10

b. Jadi jaringan dengan IP yang byte pertamanya 128-191

c. Terdapat ribuan jaringan dengan Kelas B

d. Setiap jaringan Class B bisa mempunyai ribuan host

3. Class $\mathrm{C}$

a. Bit pertama dari IP address adalah 110

b. Jadi jaringan dengan IP yang byte pertama 192-223

c. Terdapat jutaan jaringan dengan kelas $\mathrm{C}$

d. Setiap jaringan Class $\mathrm{C}$ bisa mempunyai kurang dari 254 host

Untuk memudahkan, maka awal angka dari tabel ini menerangkan Class dari IP Address.

Tabel 1. Class IP Address

\begin{tabular}{|c|c|c|c|}
\hline Class & Antara & $\begin{array}{c}\text { Jumlah } \\
\text { jaringan }\end{array}$ & $\begin{array}{c}\text { Jumlah Host } \\
\text { per Jaringan }\end{array}$ \\
\hline A & $1-126$ & 126 & 16.777 .214 \\
\hline B & $128-191$ & 16.384 & 65.536 \\
\hline C & $192-223$ & 2.097 .152 & 254 \\
\hline
\end{tabular}

Dengan demikian, untuk menentukan Class A, B atau $\mathrm{C}$ cukup dilihat dari angka 8 bit pertama.

97.123.7.12 $\rightarrow$ Class A

134.23.28.14 $\rightarrow$ Class B

202.159.1.168 $\rightarrow$ Class C

IP Address yang legal akan diberikan oleh NIC (Network Information Centre), umumnya melalui ISP (Internet Service Provider)

\subsection{Router}

Routers adalah peralatan yang bekerja pada layer 3 OSI dan sering digunakan menyambungkan jaringan luas (Wide Area Networking - WAN) atau untuk melakukan segmentasi layer 3 di LAN. WAN seperti halnya dengan LAN juga beroperasi di layer 1, 2 dan 3 OSI sehingga router yang digunakan untuk 
menyambungkan LAN dan WAN harus mampu saling mendukung. Secara umum router yang dipakai terdiri atas dua jenis yaitu :

a. Router dedicated (buatan pabrik, misalnya Cisco http://www.cisco.com, Baynetwork www.baynetworks.com

b. PC Router ( PC yang dapat difungsikan sebagai router sepanjang dia memiliki lebih dari satu interface jaringan mampu memforward paket IP, serta menjalankan program untuk mengatur routing paket. ( Onno W Purbo, 1997 : 34).

\subsection{Jitter}

Jitter merupakan variasi dari delay. Jitter dipengaruhi oleh variasi beban trafik dan besarnya tumbukan antar paket (congestion) yang ada dalam jaringan. Pengaruh jitter pada kinerja jaringan harus dilihat bersama delay. Ketika jitter besar namun delay-nya kecil maka kinerja jaringan tidak bisa dikatakan jelek karena besarnya jitter dapat dikompensasi dengan nilay delay yang kecil. Jitter akan menurunkan kinerja jaringan ketika nilainya besar dan juga nilai delaynya juga besar.

\section{Identifikasi Masalah}

Dari uraian di atas penulis mengidentifikasi beberapa masalah yang ada, diantaranya :

1. Melakukan analisa terhadap kecepatan transmisi data unggah dan unduh yang didapat dari kedua router tersebut.

2. Melakukan pencatatan waktu yang dibutuhkan oleh kedua router tersebut untuk mengupload dan mendownload suatu file.

3. Melakukan analisa jitter (variasi latensi) yang diperoleh dari kedua router tersebut.

\section{Tujuan}

Tujuan dari paper ini adalah :

1. Untuk mendapatkan data kecepatan unggah dan unduh dari kedua jenis router

2. Untuk mendapatkan karateristik delay dari kedua router.

3. Mengetahui Quality of Service dari kedua router dalam hal ini jitter dari kedua router.

\section{Metodologi Penelitian}

\subsection{Metode Pengumpulan Data}

Pada metode pengumpulan data ini penulis melakukan studi pustaka, dan observasi.

\subsubsection{Studi Pustaka}

Metode studi pustaka dilakukan dengan mengumpulkan data dan informasi yang dijadikan sebagai acuan dalam penelitian ini. Referensi-referensi tersebut berasal dari bukubuku pegangan maupun publikasi hasil penelitian, artikel, situs internet serta sumber informasi lain yang berkaitan dengan tema penelitian.

\subsubsection{Observasi}

Guna mengumpulkan informasi mengenai data yang dibutuhkan untuk menganalisa sistem, peneliti melakukan pengumpulan data dengan cara observasi hasil pengujian di tempat penelitian.

\subsection{Spesifikasi Perangkat Keras}

Perangkat keras yang digunakan dalam penelitian ini terbagi atas 2 buah jenis komputer yang pertama adalah komputer yang sudah di install system operasi jaringan ubuntu dengan spesifikasi dalam tabel 5.1.

Tabel 5.1 Spesifikasi Perangkat Keras PC router

\begin{tabular}{|l|l|}
\hline Processor & Intel Pentium IV \\
\hline Memory & 1 GB \\
\hline $\begin{array}{l}\text { Sistem } \\
\text { Operasi }\end{array}$ & Ubuntu 10.04 Lucid \\
Firewall & Iptables \\
\hline
\end{tabular}

Komputer kedua merupakan computer system tertanam yang diperuntukan sebagai router dengan merek Belkin. Speifikasi dari belkin dapat dilihat dalam tabel 4.2.

Tabel 3.2 Spesifikasi Perangkat Keras Belkin Router

\begin{tabular}{|l|l|}
\hline Processor & N/A \\
\hline Firmware & 4.00 .05 \\
\hline LAN Port & 4 \\
\hline WAN Port & 1 \\
\hline
\end{tabular}

\subsection{Spesifikasi Perangkat Lunak}

Perangkat lunak yang di gunakan dalam penilitian ini merupakan aplikasi yang dapat merekam dan transfer data dan mengukur jitter yang terjadi dalam transmisi datanya. Berikut adalah perangkat lunak yang digunakan :

- FTP Server

Di install disisi server untuk menerima layanan permintaan dari client untuk koneksi FTP.

- Filezilla FTP Client 
Di install disisi client untuk mengakses layanan ke FTP server.

- Iperf

Aplikasi yang dapat digunakan untuk mengukur jitter dari sebuah pipa transmisi.

\section{Pengujian}

Dalam pengujian, peneliti terlebih dahulu menentukan disain topologi jaringan yang digunakan dalam penelitian ini. Disain topologi yang dipilih merupakan topologi sederhana yang hanya tersambung secara local (LAN) terdiri atas satu perangkat pc-router, satu perangkat pc yang digunakan sebagai server, dan satu buah PC yang digunakan sebagai client yang terhubung dengan menggunakan switch-LAN sebagaimana terlihat dalam gambar 4.1.

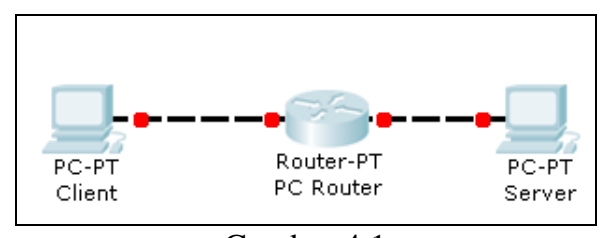

Gambar 4.1

Topologi Jaringan Pengujian

\subsection{Pengujian $P C$ - Router}

Ada beberapa skenario pengujian yang telah disiapkan berikut adalah skenario yang akan dilakukan :

1. Pihak client akan mengunduh file yang terdapat dalam server dengan ukuran file yang bervariasi dari $500 \mathrm{MB}$ dan 2 GB. Data yang dihasilkan merupakan lamanya waktu yang dibutuhkan dan kecepatan transmisi yang dihasilkan dari masing - masing file tersebut.

2. Dengan menggunakan bantuan aplikasi iperf. Iperf merupakan aplikasi yang digunakan untuk mengukur jitter dari paket yang dikirim atau diterim oleh client dan server. Iperf akan di jalankan baik di server dan diklien agar jitter dapat terukur dengan benar. Di pihak client akan diset nilai kecepatan data transmisi yang bervariasi dari 50 Mbps sampai dengan 100 Mbps.

\subsection{Pengujian Belkin Komersil Router}

Skenario pengujian yang dilakukan identik dengan skenario pengujian pada PC router yaitu :
1. Pihak client akan mengunduh file yang terdapat dalam server dengan ukuran file yang bervariasi dari $500 \mathrm{MB}$ dan $2 \mathrm{~GB}$. Data yang dihasilkan merupakan lamanya waktu yang dibutuhkan dan kecepatan transmisi yang dihasilkan dari masing - masing file tersebut.

2. Dengan menggunakan bantuan aplikasi iperf. Iperf merupakan aplikasi yang digunakan untuk mengukur jitter dari paket yang dikirim atau diterim oleh client dan server. Iperf akan di jalankan baik di server dan diklien agar jitter dapat terukur. Di pihak client akan diset nilai kecepatan data transmisi yang bervariasi dari 10 Mbps sampai dengan 100 Mbps.

Data pengujian yang didapat dari kedua Router menunjukan hasil yang sangat berbeda. Data yang di hasilkan oleh PC router baik kecepatan transmisi data, serta jitter yang dihasilkan menunjukan kecenderungan bahwa kecepatan transmisi data di PC router cenderung simetris bila dibandingkan dengan komersial router yaitu Belkin router dalam penelitian ini. Kecepatan transmisi Belkin router cendering asimetris dimana kecepatan transmisi unduh lebih cepat ketimbang kecepatan transmisi unggah. Hal ini sesuai dengan karakteristik pemakai rumahan atau SOHO (Small Office Home Office) dimana pemakaian jaringan internet lebih banyak mengunduh ketimbang mengunggah.

Tabel 6.1 Tabel Hasil Pengujian

\begin{tabular}{|c|c|c|c|}
\hline No & Skenario & PC Router & Belkin Router \\
\hline 1 & $\begin{array}{l}\text { Waktu } \\
\text { Unggah } \\
525 \mathrm{MB}\end{array}$ & $\begin{array}{l}1 \text { Menit } 56 \\
\text { Detik }\end{array}$ & $\begin{array}{l}3 \quad \text { Menit } 51 \\
\text { Detik }\end{array}$ \\
\hline 2 & $\begin{array}{l}\text { Waktu } \\
\text { Unduh } 525 \\
\text { MB }\end{array}$ & $\begin{array}{l}1 \text { Menit } 46 \\
\text { Detik }\end{array}$ & $\begin{array}{l}0 \quad \text { Menit } 55 \\
\text { Detik }\end{array}$ \\
\hline 3 & $\begin{array}{l}\text { Waktu } \\
\text { Unggah } 2 \\
\text { GB }\end{array}$ & $\begin{array}{l}3 \text { Menit } 26 \\
\text { Detik }\end{array}$ & $\begin{array}{l}4 \quad \text { Menit } 50 \\
\text { Detik }\end{array}$ \\
\hline 4 & $\begin{array}{l}\text { Waktu } \\
\text { Unduh } 2 \\
\text { GB }\end{array}$ & $\begin{array}{l}4 \text { Menit } 18 \\
\text { Detik }\end{array}$ & $\begin{array}{l}1 \quad \text { Menit } 19 \\
\text { Detik }\end{array}$ \\
\hline 5 & $\begin{array}{l}\text { Jitter di } 10 \\
\text { Mbps }\end{array}$ & $\begin{array}{ll}0,001 & - \\
0,002 \mathrm{~ms} & \end{array}$ & $\begin{array}{l}0,002-0,003 \\
\mathrm{~ms}\end{array}$ \\
\hline 6 & $\begin{array}{l}\text { Jitter di } 30 \\
\text { Mbps }\end{array}$ & $\begin{array}{ll}0,002 & - \\
0,009 \mathrm{~ms} & \end{array}$ & $\begin{array}{l}0,002-0,003 \\
\mathrm{~ms}\end{array}$ \\
\hline 7 & $\begin{array}{l}\text { Jitter di } 40 \\
\text { Mbps }\end{array}$ & $\begin{array}{ll}0,001 & - \\
0,007 \mathrm{~ms} & \end{array}$ & $\begin{array}{l}0,002-0,007 \\
\mathrm{~ms}\end{array}$ \\
\hline 8 & Jitter di 50 & 0,051 & $0,003-0,007$ \\
\hline
\end{tabular}




\begin{tabular}{|c|c|c|c|}
\hline & Mbps & $0,112 \mathrm{~ms}$ & $\mathrm{~ms}$ \\
\hline 9 & $\begin{array}{l}\text { Jitter di } 60 \\
\text { Mbps }\end{array}$ & $\begin{array}{l}\operatorname{XXXXXXXXX} \\
\operatorname{xxxx}\end{array}$ & $\begin{array}{l}0,002-0,006 \\
\mathrm{~ms}\end{array}$ \\
\hline 10 & $\begin{array}{l}\text { Jitter di } 80 \\
\text { Mbps }\end{array}$ & $\begin{array}{l}\operatorname{XXXXXXXXX} \\
\operatorname{XXXX}\end{array}$ & $\begin{array}{l}0,002-0,006 \\
\mathrm{~ms}\end{array}$ \\
\hline 11 & $\begin{array}{l}\text { Jitter di } 100 \\
\text { Mbps }\end{array}$ & $\begin{array}{l}\operatorname{XXXXXXXXX} \\
\operatorname{XxXx}\end{array}$ & $\begin{array}{l}0,013-0,207 \\
\mathrm{~ms}\end{array}$ \\
\hline
\end{tabular}

Dari tabel diatas terlihat juga kecepatan maksimum yang didapat oleh PC router sebesar 50 Mbps disbanding dengan 100 Mbps pada Belkin Router hal ini juga menunjukan bahwa proses NAT yang terjadi di PC router menyumbang latency yang lebih besar.

\section{Kesimpulan}

Berdasarkan data yang didapat dalam penelitian ini maka dapat disimpulkan sebagai berikut :

1. Kecepatan transmisi pada PC router cenderung bersifat simetris dimana kecepatan transmisi unggah dan unduh relatif sama.

2. Kecepatan transmisi pada komersial router cenderung bersifat asimetric dimana kecepatan transmisi unggah lebih kecil dibandingkan kecepatan unduh.

3. Latency atau waktu tunda pada PC router lebih besar ketimbang pada komersial router hal ini disebabkan pada PC router sistem operasi yang digunakan bersifat umum tidak khusus sehingga banyak interupsi dari proses lain yang akan dikerjakan dibandingkan dengan komersial router yang menggunakan sistem operasi sistem tertanam yang memang didesain khusu untuk keperluan merouting paket.
[1] Nugroho, B., 2005, Instalasi \& Konfigurasi Jaringan Windows \& Linux, Penerbit ANDI, Yogyakarta

[2] Purbo, O., W., 1997, TCP/IP Standar, Desain dan Implementasi, Penerbit PT Elex Media Komputindo, Jakarta

[3] Purbo, O., W., 2005, Wireless Internet dan Hotspot, Penerbit PT Elex Media Komputindo, Jakarta

[4] Rafiudin, R, 2006, Protokol-Protokol Esensial Internet, Penerbit ANDI, Yogyakarta

[5] Satya, I. A., 2006, Mengenal dan Menggunakan Mikrotik Winbox Router Modern Berbasis PC, Penerbit Datakom Lintas Buana, Jakarta.

[6] Wardiana, W, 2002, Perkembangan Teknologi Informasi, Lembaga Ilmu Pengetahuan Indonesia

[7] M. Azis Muslim., Analisa Teknis Perbandingan Router Linux dengan Router Mikrotik pada Jaringan Wireless, Jurnal Teknologi Informasi DINAMIK Vol. XII No. 1, Januari 2007,10-21, Semarang.

\section{Daftar Pustaka}

